\title{
Sobre la eliminación de las vacunas multidosis que contienen timerosal
}

$\mathrm{E}$ 1 documento actual fue preparado para ser presentado ante la Comisión de Salud del Senado, durante la sesión que trataba el segundo trámite del Proyecto de ley que elimina las vacunas multidosis con timerosal o compuestos organomercúricos (Boletín $N^{\circ}$ 7.036-11), originalmente citada en junio de 2013. Para este fin, se envío un documento preliminar a la Comisión; con posterioridad a lo cual, la sesión ha sido suspendida en dos ocasiones por lo que la Sociedad Chilena de Infectología no ha podido manifestar su opinión ante la Comisión de Salud. Habiéndose citado el 13 de agosto una sesión para emitir un informe complementario del Nuevo Segundo Informe sobre este proyecto de ley, y no habiéndose citado en esta ocasión a nuestra Sociedad o para una sesión futura, el Directorio de Sociedad Chilena de Infectología ha decidido el 7 de agosto de 2013 hacer pública esta posición para el conocimiento de la comunidad médica.

\section{Posición de la Sociedad Chilena de Infectología}

La Sociedad Chilena de Infectología (SOCHINF) agradece la invitación que le hiciera la Comisión de Salud del Senado con el objeto de conocer su opinión respecto del proyecto de ley, en segundo trámite constitucional, que elimina las vacunas multidosis con timerosal o compuestos organomercúricos (Boletín No 7.036-11).

A modo de introducción, queremos reiterar nuestra convicción de que las vacunas han sido una de las intervenciones de salud pública más eficaces en el control de enfermedades infecciosas en el mundo, en términos de evitar millones de muertes y condiciones discapacitantes. El control de las enfermedades inmunoprevenibles es extremadamente sensible a las coberturas alcanzadas por los programas de vacunación; existen varios ejemplos que muestran cómo estas enfermedades están reemergiendo en países que han visto disminuida sus coberturas. Uno de los pilares fundamentales en que radica el éxito de un Programa de Inmunizaciones, es la confianza que tiene la población en esta acción de salud. Desde hace unos años, venimos asistiendo en nuestro país a una lenta y progresiva pérdida de confianza en las vacunas, principalmente relacionada con aspectos de seguridad, lo cual ha llevado a algunos padres a optar por no vacunar a sus hijos. Un ejemplo de esto es la supuesta relación del timerosal con el autismo, tema que está socavando la confianza que históricamente ha tenido nuestra población en las vacunas.

En relación al tema del timerosal y vacunas, la Sociedad Chilena de Infectología viene a exponer lo siguiente:

\section{Riesgo asociado al uso de compuestos mercuriales en inmunización}

Adjunto a esta carta se encuentra la revisión realizada por el Comité Consultivo de Inmunizaciones (CCI) de nuestra Sociedad, publicada el año 2007 en Revista Chilena de Infectología (Anexo 1) ${ }^{1}$. En esta revisión, si bien se reconoce la toxicidad del mercurio para el ser humano en cualquiera de sus formas, orgánica e inorgánica, el CCI concluye que no existe evidencia científica que avale la toxicidad del timerosal presente en las vacunas por lo que suscribe la recomendación de la Organización Mundial de la Salud (OMS) de mantener el uso de vacunas que contienen timerosal, a fin de no poner en riesgo el control de las enfermedades inmunoprevenibles.

Nuestra Sociedad solidariza con los padres y familias de niños con autismo y entiende que ellos no escatimen esfuerzos por aclarar el origen de esta dolorosa condición. Sin embargo, manifestamos nuestra preocupación por el alto impacto mediático y social que este tema ha tenido en la opinión pública y que está generando desconfianza en las vacunas de uso programático, poniendo así en riesgo el éxito de nuestro Programa Nacional de Inmunizaciones en el control de enfermedades inmunoprevenibles, que sabemos fueron devastadoras y que aún lo siguen siendo en países menos privilegiados.

Al revisar los argumentos que se han esgrimido para avalar este proyecto de ley, vemos que la revisión y discusión en esta materia no ha considerado toda la información científica disponible. En lo central, la Comisión de Salud reconoce que no existe suficiente evidencia científica que relacione al timerosal con trastornos del espectro autista, y para respaldar este proyecto de ley utiliza como único argumento "lo primero es no dañar".

En relación a este punto, debemos señalar que en la discusión no se tomó en consideración el informe final del Comité de Revisión de la Seguridad en Inmunizaciones del Instituto de Medicina (IOM) de EEUU, que en el año 2004 -en base a datos provenientes de EEUU, Dinamarca, Reino Unido y Suecia- rechaza enfáticamente la relación entre timerosal y autismo (Anexo 2, página 6$)^{2}$. 
Coincidiendo con lo anterior, la evidencia reunida en los últimos 14-15 años no ha podido demostrar la existencia de daño por el uso de timerosal en las vacunas, incluyendo dentro de éste los graves trastornos del neurodesarrollo que se le atribuyen, y en aquellos países que retiraron las vacunas que contienen timerosal, como Canadá, EEUU y Dinamarca entre otros, se ha observado que la prevalencia del autismo sigue en rápido ascenso.

Con todos estos antecedentes, en junio del año 2012 la Academia Americana de Pediatría, revocó la recomendación que hiciera en el año 1999 en cuanto a eliminar el uso de timerosal en las vacunas, concluyendo que a la luz de la evidencia actual, la exposición al timerosal mediante la vacunación no es perjudicial para la salud humana. En el Anexo $3^{3}$, se acompaña un comentario relacionado con esta materia publicado en la revista Pediatrics de enero del presente año.

Por otra parte, es importante señalar que las compañías fabricantes de vacunas han modificado y mejorado los procesos de manufactura, de tal manera que, hoy en día, el contenido de timerosal en la mayoría de las vacunas sólo alcanza el nivel de trazas $(<1 \mu \mathrm{g})$. Si bien hoy en día existen en el mercado otros preservantes, ninguno de ellos aparece como una alternativa viable frente al timerosal ya que tendrían el potencial de alterar la estabilidad, seguridad y eficacia de una vacuna, de tal manera que evaluar estos otros preservantes en nuevas formulaciones de vacunas demandaría tiempo y recursos.

Otro aspecto no menos importante es el hecho de que en esta discusión la Comisión de Salud ha validado la opinión de algunos "expertos" que apoyan el supuesto efecto nocivo del timerosal, a saber los Drs Mark Geier y David Geier. En base a la información disponible, el 22 de junio de 2012 el Dr. Mark Geier fue sancionado por la Junta de Médicos del Estado de Maryland, EEUU, bajo el cargo de un desconocimiento casi total de las normas médicas y éticas básicas, revocándole la licencia que le autoriza el ejercicio de la profesión. Este hecho impone una razonable duda en cuanto a sus opiniones. (Anexo 4: se adjunta fallo del Maryland State Board of Physicians $)^{4}$.

\section{Impacto ambiental y en la salud humana derivada del mercurio. Importancia de las vacunas en este contexto}

El Programa del Medio Ambiente de la Naciones Unidas (UNEP- sigla en inglés) ha publicado recientemente un reporte denominado Global Mercury Assessment 2013 que señala que el mercurio sigue siendo un importante desafío global, regional y nacional en cuanto a las amenazas que representa para la salud humana y el medio ambiente. Entrega la información más reciente disponible sobre las emisiones atmosféricas de mercurio en todo el mundo, contaminación del medio acuático y del destino del mercurio en el medioambiente. El reto para abordar y regular las emisiones de mercurio radica en la amplia variedad de fuentes generadoras de este metal, que abarca desde los procesos industriales a productos de uso cotidiano. Para muchos, es desconocido que el mercurio se encuentra en aparatos eléctricos como interruptores, lámparas fluorescentes y termostatos, en dispositivos médicos como termómetros y aparatos para medir la presión arterial (esfingomanómetros), así como también en amalgamas dentales. El mercurio también se utiliza en la elaboración de productos tales como baterías, pinturas, jabones y cosméticos.

Este informe de Naciones Unidas, no reconoce al timerosal como un factor nocivo para la salud de las personas, y respalda los reportes emitidos por la OMS en esta materia, siendo muy claro en señalar que el mayor riesgo para el ser humano deriva del consumo de pescado que contiene altos niveles de mercurio en su forma orgánica, el metil-mercurio. Una vez ingerido, este compuesto se absorbe en un $95 \%$ y sus efectos deletéreos se observan principalmente en población vulnerable como fetos, niños y mujeres embarazadas.

Tomando en consideración lo señalado anteriormente, la Sociedad Chilena de Infectología demanda de las autoridades la implementación de una política coherente en materia de protección de la salud de las personas en relación al mercurio, ya que en términos de riesgos, claramente excede al tema del timerosal. Esta política debiera traducirse en el retiro inmediato de termómetros y esfingomanómetros de mercurio, sustitución de amalgamas dentales, control y regulación de las distintas fuentes de emisión de mercurio, monitoreo permanente de la concentración de mercurio en el aire, suelo y agua, especialmente en zonas de minería del oro, medición de concentración de mercurio en productos alimenticios, especialmente derivados de la fauna marina, como también de pesticidas y fungicidas. Con esta medida se estaría entregando una clara señal de la importancia que tiene para el gobierno proteger la salud de las personas y de su responsabilidad frente al medioambiente (Anexos 5 y 6: documentos de UNEP) $)^{5,6}$.

\section{Respuesta frente a emergencias sanitarias}

La prohibición de utilizar vacunas que contengan timerosal a cualquier título podría tener serias implicancias frente a situaciones de emergencia sanitaria en que se requiera disponer de vacunas en un corto plazo para ser administradas en forma masiva.

Situaciones como éstas no son ajenas a nuestra realidad y lo hemos vivido en los últimos meses en relación a los brotes de enfermedad meningococóccica y coqueluche, 
en que las autoridades de salud, en muy corto plazo, han debido tomar medidas de control sanitario, lo que demuestra la vulnerabilidad de nuestra población.

Si bien, en el período 1999-2000 en EEUU se hizo la recomendación de retirar el timerosal de todas las vacunas, actualmente y previendo este tipo de situaciones es que en ese país está autorizado el uso de timerosal en vacuna anti influenza en presentación de multidosis (Anexo 7) ${ }^{7}$.

\section{Potencial resurgimiento de coqueluche como consecuencia del retiro de vacunas que contienen timerosal}

De aprobarse esta ley que prohíbe el uso de vacunas que contienen timerosal, el Programa Nacional de Inmunizaciones deberá retirar de su calendario la vacuna pentavalente, destinada a proteger contra cinco enfermedades dentro de las cuales está la coqueluche o tos convulsiva. En esta formulación, la protección contra coqueluche recae en el componente llamado pertussis de células enteras.

Hoy en día en el mercado mundial, sólo se dispone de una vacuna libre de timerosal que protege contra estas mismas enfermedades denominada vacuna hexavalente, y que además agrega protección contra la poliomielitis. En esta formulación la protección contra la coqueluche está dada por el componente pertussis acelular.

A raíz del resurgimiento global de casos de coqueluche y del cual Chile no ha estado exento, existe evidencia recientemente publicada que demuestra una mayor protección entre quienes han recibido como esquema primario en el primer año de vida vacuna pertussis de células enteras, comparado con quienes recibieron vacuna acelular (Anexo 8) ${ }^{8}$. Más aún, se ha postulado que el brote de coqueluche ocurrido en Australia (2009-2011), podría estar asociado en parte, al cambio programático desde una vacuna de células enteras a una vacuna acelular (Anexo 9) ${ }^{9}$.

Por los motivos antes expuestos, es que la SOCHINF hace un llamado a realizar una discusión técnica y política profunda en relación a la conveniencia de ejecutar este cambio, desde vacuna pentavalente a hexavalente, cuya única justificación por ahora, radica en este proyecto de ley.

\section{Prioridades en materia de inmunizaciones}

En materia de asignación de recursos en salud, hay que tener presente el concepto de "costo de oportunidad", definido como el valor de la mejor opción a la que se renuncia cuando se realiza una intervención, o dicho de otra forma, es lo que se podría hacer y no se hace, porque se hacen cosas menos adecuadas. Desde la perspectiva de un razonamiento económico, se trata de asegurar que los beneficios obtenidos al seleccionar una opción sean mayores que los que se habrían obtenido con otras ${ }^{10}$.

Sin duda que la incorporación de la vacuna hexavalente al Programa Nacional de Inmunizaciones requerirá de un aumento del presupuesto en salud, lo cual no debiera ser materia de discusión ya que el país ha alcanzado y consolidado un importante desarrollo económico. Lo que sí queremos recalcar y poner en la agenda de discusión es que aún existen deudas importantes en materia de inmunización con grupos de pacientes con factores de riesgo, como aquellos portadores de VIH, pacientes oncológicos, enfermos con patologías renales y cardiacas crónicas entre otros, como también con nuestros jóvenes $\mathrm{y}$ adolescentes.

Está pendiente la incorporación de la vacuna que previene el cáncer cervicouterino asociado a la infección persistente por virus papiloma humano. En Chile esta enfermedad determina más de 600 muertes al año y es la segunda causa de muerte por cáncer en mujeres en edad reproductiva. La tasa de mortalidad por este cáncer (7,6 por 100.000 mujeres) es cuatro veces mayor que la de países desarrollados y presenta una marcada estratificación social. También está pendiente la incorporación de la vacuna contra hepatitis A, enfermedad que puede determinar complicaciones graves como hepatitis fulminante -que tiene una alta mortalidad- o bien requiere de trasplante hepático, medida terapéutica de alto costo.

En síntesis, la SOCHINF declara que este proyecto de ley que prohíbe en nuestro país el uso de vacunas con timerosal, carece de base científica ya que la evidencia descarta por completo su asociación con daño neurológico en niños, y esto ha sido ratificado recientemente por distintos organismos como la OMS, Naciones Unidas, FDA, CDC de EEUU y la Academia Americana de Pediatría. Además esta medida pone en riesgo a la población frente a una emergencia sanitaria en que se requiera el uso de productos biológicos que contengan timerosal. Por otra parte, si se quiere ser coherente en términos de proteger la salud de las personas en relación al mercurio, la eliminación del timerosal debiera estar inserta dentro de una política medioambiental amplia, orientada al control y regulación efectiva de las distintas fuentes de emisión, hecho no contemplado en esta ley. Finalmente, el retiro de todas las vacunas que contengan timerosal necesariamente incidirá en el presupuesto nacional, y estos recursos se estarán destinando a la satisfacción de una demanda social no sustentada por la literatura científica, postergando una vez más otras prioridades en materia de enfermedades inmunoprevenibles.

Por todo lo antes señalado, la Sociedad Chilena de Infectología no apoya en nuestro país la existencia de 
una ley que prohíba el uso de timerosal en las vacunas u otros productos biológicos.

Agradeciendo la posibilidad de participar en este debate, saluda atentamente a Ud.

\section{Dr. Mario Calvo}

Presidente Sociedad Chilena de Infectología

\section{Referencias asociadas a los anexos señalados}

1.- Muñoz M A, Abarca V K, Jiménez de la J J, Luchslnger F V, O'Ryan G M, Ripoll M E, et al. Safety of thimerosal containing vaccines. Statement of the Consultive Committee of Immunizations on behalf of the Chilean Infectious Diseases Society. Rev Chilena Infectol 2007; 24 (5): 372-6.

2.- Food \& Drug Administration. http://www.fda.gov/ BiologicsBloodVaccines/SafetyAvailability/VaccineSafety/ UCM096228. Accedido el 10 de junio de 2013.

3.- American Academy of Pediatrics. Ban on all mercury-based products would risk global immunization efforts. APPnews July, 2012. http://aapnews.aappublications.org/content/ early/2012/06/01/aapnews.20120601-1

4.- Maryland Board of Physicians. Final Decision and Orders. Cases 2007-0083, 2008-0454, 2009-0308. http://www. casewatch.org/board/med/geier/geier_revocation.pdf. Accedido 8 de agosto 2013.

5.- United Nations Environmental Program. Global Mercury Assesment 2013. http://www.unep.org/PDF/PressReleases/ GlobalMercuryAssessment2013.pdf. Accedido 8 de agosto 2013.

6.- United Nations Environmental Program. Mercury, Time to Act. http://www.unep.org/PDF/PressReleases/Mercury_ TimeToAct_hires.pdf. Accedido 8 de agosto 2013.

7.- Centers for Disease Control and Prevention (CDC). Prevention and Control of Influenza with Vaccines: Recommendations of the Advisory Committee on Immunization Practices (ACIP) -United States, 2012-13 Influenza Season. MMWR Morb Mortal Wkly Rep 2012; 61 (32): 613-8.

8.- Klein N P, Bartlett J, Fireman B, Rowhani-Rahbar A, Baxter R. Comparative effectiveness of acellular versus whole-cell pertussis vaccines in teenagers. Pediatrics 2013; 131 (6): e1716

9.- Sheridan S L, Ware R S, Grimwood K, Lambert S B. Number and order of whole cell pertussis vaccines in infancy and disease protection. JAMA 2012; 308 (14): 1432.

10.- Sacristán J A, Ortún V, Rovira J, Prieto L, García-Alonso F; Grupo ECOMED. Economic assessment in medicine. Med Clin (Barc) 2004; 122 (10): 379-82. 